\title{
A High-Capacity Ammonium Vanadate Cathode for Zinc-Ion Battery
}

Cite as

Nano-Micro Lett.

(2020) 12:67

Received: 16 December 2019

Accepted: 2 February 2020

Published online: 4 March 2020

(C) The Author(s) 2020

\author{
Qifei $\mathrm{Li}^{1}$, Xianhong Rui ${ }^{1,2}{ }^{凶}$, Dong Chen ${ }^{1}$, Yuezhan Feng ${ }^{3}, \mathrm{Ni}$ Xiao ${ }^{4}$, Liyong Gan ${ }^{5}$, \\ Qi Zhang ${ }^{1}$, Yan Yu ${ }^{2,6,7}$, Shaoming Huang ${ }^{1}$ \\ $\triangle$ Xianhong Rui, xhrui@gdut.edu.cn; Yan Yu, yanyumse@ustc.edu.cn; Shaoming Huang, \\ smhuang@gdut.edu.cn \\ 1 Guangzhou Key Laboratory of Low-Dimensional Materials and Energy Storage Devices, \\ School of Materials and Energy, Guangdong University of Technology, Guangzhou 510006, \\ People's Republic of China \\ 2 Hefei National Laboratory for Physical Sciences at the Microscale, Department of Materials Science \\ and Engineering, CAS Key Laboratory of Materials for Energy Conversion, University of Science \\ and Technology of China, Hefei 230026, People's Republic of China \\ 3 Key Laboratory of Materials Processing and Mold (Zhengzhou University), Ministry of Education, \\ Zhengzhou University, Zhengzhou 450002, People's Republic of China \\ 4 Aviation Fuel Research and Development Center, China National Aviation Fuel Group Limited, \\ Beijing 102603, People's Republic of China \\ 5 Department Institute for Structure and Function and of Physics, Chongqing University, Chongqing 400030, \\ People's Republic of China \\ 6 Dalian National Laboratory for Clean Energy (DNL), Chinese Academy of Sciences, Dalian 116023, \\ Liaoning, People's Republic of China \\ 7 State Key Laboratory of Fire Science, University of Science and Technology of China, Hefei 230026, \\ People's Republic of China
}

\section{HIGHLIGHTS}

- 3D flower-like architecture assembled by $\mathrm{NH}_{4} \mathrm{~V}_{4} \mathrm{O}_{10}$ nanobelts (3D-NVO) was fabricated.

- The $\mathrm{Zn}^{2+}$ ion was intercalated into NVO cathode within the interlayer region $\left(\mathrm{NH}_{4} \mathrm{~V}_{4} \mathrm{O}_{10} \leftrightarrow \mathrm{Zn}_{x} \mathrm{NH}_{4} \mathrm{~V}_{4} \mathrm{O}_{10}\right)$.

- The 3D-NVO cathode could deliver a large reversible capacity of $485 \mathrm{mAh} \mathrm{g}^{-1}$ at a current density of $100 \mathrm{~mA} \mathrm{~g}^{-1}$ for zinc-ion battery.

\begin{abstract}
Given the advantages of being abundant in resources, environmental benign and highly safe, rechargeable zinc-ion batteries (ZIBs) enter the global spotlight for their potential utilization in large-scale energy storage. Despite their preliminary success, zinc-ion storage that is able to deliver capacity $>400 \mathrm{mAh} \mathrm{g}^{-1}$ remains a great challenge. Here, we demonstrate the viability of $\mathrm{NH}_{4} \mathrm{~V}_{4} \mathrm{O}_{10}(\mathrm{NVO})$ as high-capacity cathode that breaks through the bottleneck of ZIBs in limited capacity. The firstprinciples calculations reveal that layered NVO is a good host to provide fast $\mathrm{Zn}^{2+}$ ions diffusion channel along its [010] direction in the interlayer space. On the other hand, to further enhance $\mathrm{Zn}^{2+}$ ion intercalation kinetics and long-term cycling stability, a three-dimensional (3D) flower-like architecture that is self-assembled by NVO nanobelts (3D-NVO) is rationally designed and fabricated through a microwave-assisted hydrothermal
\end{abstract}

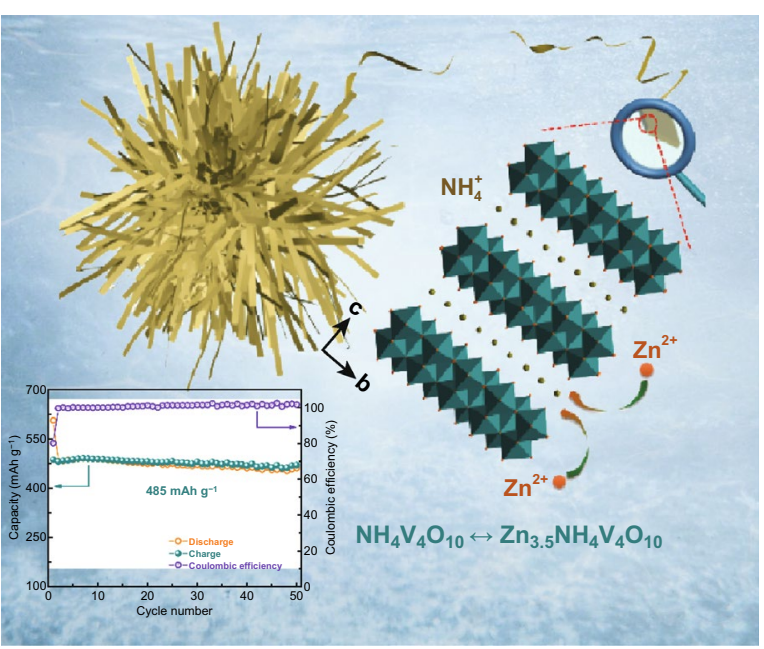


method. As a result, such 3D-NVO cathode possesses high capacity (485 $\mathrm{mAh} \mathrm{g}^{-1}$ ) and superior long-term cycling performance (3000 times) at $10 \mathrm{~A} \mathrm{~g}^{-1}(\sim 50 \mathrm{~s}$ to full discharge/charge). Additionally, based on the excellent 3D-NVO cathode, a quasi-solid-state ZIB with capacity of $378 \mathrm{mAh} \mathrm{g}^{-1}$ is developed.

KEYWORDS Zinc-ion battery; Ammonium vanadate; $\mathrm{NH}_{4} \mathrm{~V}_{4} \mathrm{O}_{10}$

\section{Introduction}

Battery technologies are the key to delivering significant advances in a wide range of industries, from portable electronics and electric vehicles to renewable power [1-5]. Given the looming concerns over the availability and safety hazards of lithium resources, rechargeable zinc-ion batteries (ZIBs) are relatively abundant in resources and environmental benign as compared to alkaline metals. To add in the easy manufacturing process, good safety characteristics and mature recycling process, ZIBs are the cost-effective solution for stationary applications in the long run as well [6-9]. Nevertheless, for most ZIBs, their specific capacity, cycling stability and rate capability are limited by cathode materials [10-13]. Developing cathode materials with outstanding electrochemical performance is imperative but yet remains a major challenge to be overcome.

The exploration focus of ZIB cathode materials remains on manganese-based oxides, such as $\alpha-\mathrm{MnO}_{2}[14,15]$, $\beta-\mathrm{MnO}_{2}$ [16], $\gamma-\mathrm{MnO}_{2}$ [17], $\alpha-\mathrm{Mn}_{2} \mathrm{O}_{3}$ [18], $\mathrm{Mn}_{3} \mathrm{O}_{4}$ [19], and $\mathrm{ZnMn}_{2} \mathrm{O}_{4}[20,21]$, which can deliver initial charge/ discharge capacities up to $200-350 \mathrm{mAh} \mathrm{g}^{-1}$ under low rates. Nevertheless, their capacities decay drastically owing to the Mn dissolution via the disproportionation reaction upon repeated electrochemical cycling. Recent advances in reversible $\mathrm{Zn}^{2+}$ ion (de)intercalation in $\mathrm{VO}_{2}[22,23]$, $\mathrm{V}_{2} \mathrm{O}_{5}$ [24-26], $\mathrm{V}_{2} \mathrm{O}_{5} \cdot n \mathrm{H}_{2} \mathrm{O}$ [27, 28], $\mathrm{Zn}_{0.25} \mathrm{~V}_{2} \mathrm{O}_{5} \cdot n \mathrm{H}_{2} \mathrm{O}$ [29], $\mathrm{H}_{11} \mathrm{Al}_{2} \mathrm{~V}_{6} \mathrm{O}_{23.2}$ [30], $\mathrm{Ca}_{0.25} \mathrm{~V}_{2} \mathrm{O}_{5} \cdot n \mathrm{H}_{2} \mathrm{O}$ [31], $\mathrm{LiV}_{3} \mathrm{O}_{8}$ [32], $\mathrm{Na}_{0.33} \mathrm{~V}_{2} \mathrm{O}_{5}$ [33], $\mathrm{Na}_{2} \mathrm{~V}_{6} \mathrm{O}_{16} \cdot 3 \mathrm{H}_{2} \mathrm{O}$ [34], $\mathrm{Mn}_{0.15} \mathrm{~V}_{2} \mathrm{O}_{5} \cdot n \mathrm{H}_{2} \mathrm{O}$ [35], $\mathrm{K}_{2} \mathrm{~V}_{8} \mathrm{O}_{21}$ [36], and $\mathrm{VS}_{2}$ [37] have motivated further exploration into vanadium-based cathodes for ZIBs. For example, a freestanding paper cathode of layered calcium vanadium oxide bronze demonstrates $340 \mathrm{mAh} \mathrm{g}^{-1}$ at a low current density [31] and layered $\mathrm{Na}_{2} \mathrm{~V}_{6} \mathrm{O}_{16} \cdot 3 \mathrm{H}_{2} \mathrm{O}$ as the host for $\mathrm{Zn}^{2+}$ ion conveys $\sim 300 \mathrm{mAh} \mathrm{g}^{-1}$ (current rate: $180 \mathrm{~mA} \mathrm{~g}^{-1}$ ) and a high-rate performance [e.g., operating at 14.4 $\mathrm{A} \mathrm{g}^{-1}\left(128 \mathrm{mAh} \mathrm{g}^{-1}\right)$ ] [34]. Despite current achievements, their reversible capacity is still far from being satisfactory $\left(<400 \mathrm{mAh} \mathrm{g}^{-1}\right)$ owing to tardive $\mathrm{Zn}^{2+}$ diffusion.
The rich chemistry of ammonium vanadate $\left(\mathrm{NH}_{4} \mathrm{~V}_{4} \mathrm{O}_{10}\right.$, $\mathrm{NVO}$ ) arising from the double layers of $\mathrm{V}_{4} \mathrm{O}_{10}$ and vanadium in high oxidation state makes it a great potential candidate for accommodating $\mathrm{Zn}^{2+}$ ions. In addition, the pillaring effect of $\mathrm{NH}_{4}{ }^{+}$ions enlarges the interlayer spacing or "gallery" space (Fig. S1) [38], which promote $\mathrm{Zn}^{2+}$ ion diffusion along the tunnel (i.e., favorable electrochemical capacity and electrode kinetics). The successful reversible storage of $\mathrm{Li}^{+}\left(r_{\mathrm{Li}^{+}}=0.74 \AA\right)$ [39-41], divalent $\mathrm{Mg}^{2+}\left(r_{\mathrm{Mg}^{2+}}=0.72 \AA\right)$ [42], as well as larger-sized $\mathrm{Na}^{+}\left(r_{\mathrm{Na}^{+}}=1.02 \AA\right)$ [43, 44], and $\mathrm{Ca}^{2+}\left(r_{\mathrm{Ca}^{2+}}=1.00 \AA\right)$ [45] in $\mathrm{NH}_{4} \mathrm{~V}_{4} \mathrm{O}_{10}$ as verified by theoretical calculations and experimental electrochemical measurements further predicts the feasibility of taking up $\mathrm{Zn}^{2+}$ cations with similar size $\left(r_{\mathrm{Zn}^{2+}}=0.76 \AA\right)$.

To prove the above prediction, we firstly performed the first-principles calculations to evaluate the $\mathrm{Zn}^{2+}$ ion intercalation behaviors in monoclinic NVO. Similar to the accommodation of $\mathrm{Na}^{+}$ions [46], the intercalated $\mathrm{Zn}^{2+}$ ions energetically prefer the rest gallery space and sites. Using bulk $\mathrm{Zn}$ as the reference state, the binding energy was calculated to be $-3.18 \mathrm{eV}$, which is much stronger than that in layered $\mathrm{V}_{2} \mathrm{O}_{5}(-2.06 \mathrm{eV})$ [47]. Figure $\mathrm{S} 1$ illustrates three possible migration paths: diffusion between two VO layers (i.e., along [010] and [100] directions) and that through VO layer (i.e., [001] direction). It is found that the migration of a $\mathrm{Zn}^{2+}$ ion directly along [100] direction seems impossible because the path is blocked by the $\mathrm{NH}_{4}{ }^{+}$ions. Although the $\mathrm{NH}_{4}{ }^{+}$ion that resides in the lattice spacing may be skirted between two $\mathrm{NH}_{4}{ }^{+}$ions via diffusion, intercalation of $\mathrm{Zn}^{2+}$ ion at this site is extremely unstable as the initially placed $\mathrm{Zn}^{2+}$ ion would relax spontaneously to a nearby gallery site. Therefore, this possibility could be safely ruled out. The migration energy barrier, which reflects $\mathrm{Zn}^{2+}$ ion diffusivity, is determined by the maximum energy along each diffusion path. Figure 1 shows the calculated results of $\mathrm{Zn}^{2+}$ diffusion along [010] direction and through a VO layer in monoclinic NVO. Notably, lower energy barrier $(0.63 \mathrm{eV})$ is demonstrated when 

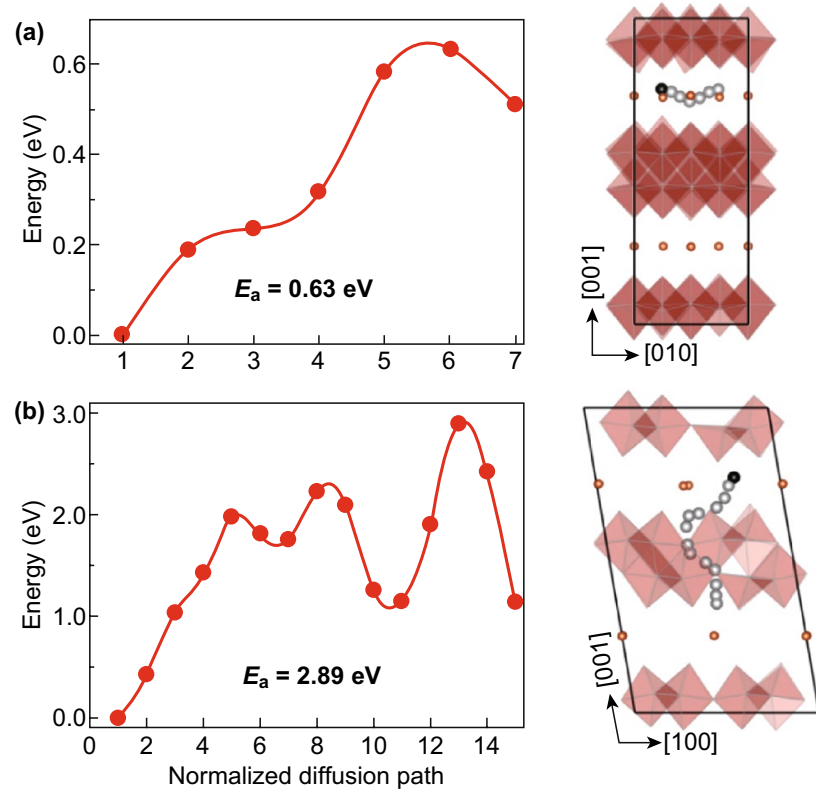

Fig. 1 Calculated minimum energy paths of $\mathrm{Zn}^{2+}$ ion diffusion along a [010] and $\mathbf{b}$ [001] in monoclinic $\mathrm{NH}_{4} \mathrm{~V}_{4} \mathrm{O}_{10}$. Orange and black balls represent $\mathrm{NH}_{4}{ }^{+}$ions and the most energetically favorable pathway for $\mathrm{Zn}^{2+}$ ion intercalation, respectively. The VO layers are indicated by red polyhedrons. (Color figure online)

$\mathrm{Zn}^{2+}$ ion diffuses along the [010] direction. In contrast, diffusion of a $\mathrm{Zn}^{2+}$ ion through a VO layer is also hindered as steric effect imposes a significantly large energy barrier $(2.89 \mathrm{eV})$ for ion migration [48]. These results clearly suggest the feasibility of monoclinic NVO in providing fast $\mathrm{Zn}^{2+}$ ion intercalation along the [010] direction within the interlayer region.

The electrochemical performance of ZIBs, especially at high charging/discharging rates, is mainly determined by the $\mathrm{Zn}^{2+}$ ion solid-state diffusion process (i.e., ratedetermining step) in the electrode materials. Thus, it is highly desirable to minimize the dimensions of NVO active materials in order to accelerate the $\mathrm{Zn}^{2+}$ ion kinetics. Thus, we attempt to synthesize one-dimensional (1D) NVO nanobelts to achieve this goal. Meanwhile, to avoid the agglomeration of NVO nanobelts, NVO nanobelts are designed to self-assemble into three-dimensional (3D) flower-like architecture (abbreviated as 3D-NVO, Fig. 2a), which can maintain structural integrity during repeated $\mathrm{Zn}^{2+}$ (de) intercalation. Although there are some reports on the fabrication of $1 \mathrm{D}$ NVO $[43,49,50]$, engineering them into
3D-NVO presents a great challenge but might bring a significance to the development of electrode materials for ZIBs and quasi-solid-state ZIBs.

\section{Experimental}

\subsection{Synthesis of 3D-NVO}

In a typical synthesis, $2 \mathrm{mmol}$ ammonium metavanadate $\left(\mathrm{NH}_{4} \mathrm{VO}_{3}\right)$ and $2 \mathrm{mmol}$ oxalic acid $\left(\mathrm{H}_{2} \mathrm{C}_{2} \mathrm{O}_{4}\right)$ were added into deionized (DI) water $(30 \mathrm{~mL})$ under magnetic stirring, creating a kelly green solution. Then, it was put into an autoclave $(50 \mathrm{~mL})$ and placed in a microwave oven heated under $180^{\circ} \mathrm{C}$ for $30 \mathrm{~min}$. Afterward, the product was washed with DI water and ethanol and then frozen under liquid nitrogen to subject a vacuum drying process for about $48 \mathrm{~h}$.

\subsection{Calculation Methods}

Vienna Ab-Initio Simulation Package was adopted to conduct first-principles calculations. The spin-polarized Perdew-Burke-Ernzerhof generalized gradient approximation was used for the exchange-correlation functional [51-53]. Van der Waals correction was included using the Grimme scheme (D2) for simulations of monoclinic NVO (space group: $\mathrm{C} 2 / \mathrm{m}$ ) [54]. The lattice parameters of NVO were calculated to be $a=11.79 \AA, b=3.68 \AA$, $c=9.93 \AA$ and $\beta=99.49^{\circ}$, consistent well with experimental values. A $(1 \times 2 \times 2)$ supercell involving 152 atoms $\left(\mathrm{N}_{8} \mathrm{H}_{32} \mathrm{~V}_{32} \mathrm{O}_{80}\right)$ was constructed to simulate diffusion behavior of zinc ions in NVO. It was relaxed with force convergence criteria of $0.01 \mathrm{eV} \AA^{-1}$. Moreover, $500 \mathrm{eV}$ cutoff energy and $\Gamma$-centered $3 \times 5 \times 2 k$-mesh were used. The climbing image nudged elastic band method was adopted to achieve the pathway with the minimum energy for $\mathrm{Zn}$ ion diffusion [55]. Because of the strong electronic correlations in the localized $d$ orbitals of $\mathrm{V}$ ions, an effective parameter of $\mathrm{U}-\mathrm{J}=4.0 \mathrm{eV}$ was applied for an on-site Coulomb interaction, which was believed to be able to provide more appropriate description of electronic properties in vanadium oxides [56]. 

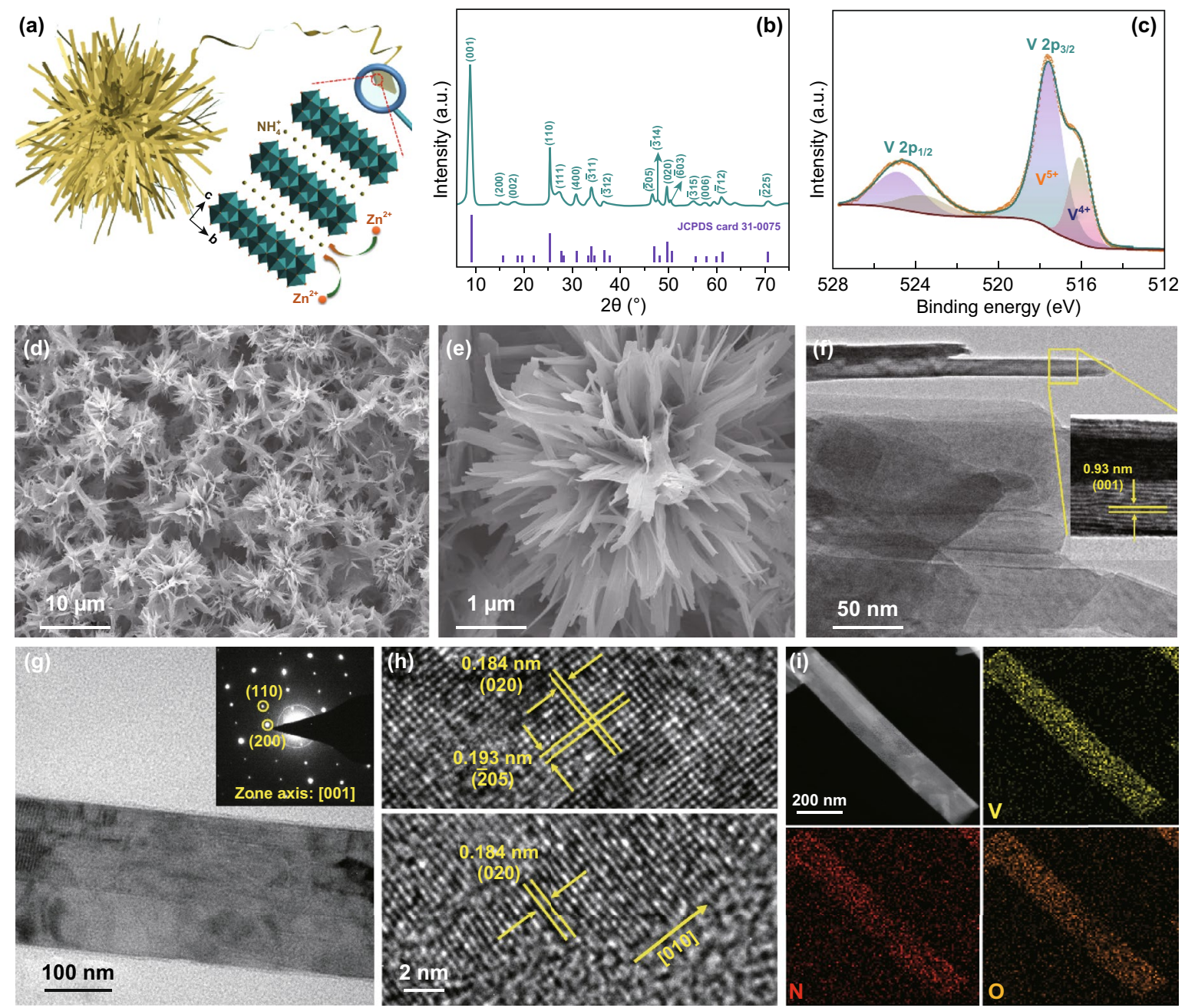

Fig. 2 a Schematic illustration of the designed 3D-NVO architecture. Chemical and physical characterization of the 3D-NVO: b XRD pattern, $\mathbf{c}$ high-resolution XPS spectrum of the V 2p region, $\mathbf{d}$, e SEM images, $\mathbf{f}$ TEM image (inset: HRTEM image of a lateral-lying nanobelt), $\mathbf{g}$ TEM image of an individual nanobelt (inset: the corresponding SAED pattern), $\mathbf{h}$ HRTEM images, and $\mathbf{i}$ STEM and the corresponding elemental mapping images

\subsection{Materials Characterization}

The X-ray diffraction (XRD) patterns were acquired from an advanced X-ray diffractometer with $\mathrm{Cu} K_{\alpha}$ radiation (Bruker D8). A field-emission scanning electron microscopy (SEM) system (Hitachi, Model SU8220) was used to investigate the morphology of the products. To further determine their microstructures, transmission electron microscopy (TEM) characterization (FEI, Model Talos F200S) operating at $200 \mathrm{kV}$ was carried out. The X-ray photoelectron spectroscopy (XPS) was measured on ESCALAB 250Xi (Thermo Fisher).

\subsection{Electrochemical Measurements}

The electrochemical performance of the 3D-NVO materials was tested by assembling them into coin-type cells in air. Typically, $80 \mathrm{wt} \%$ 3D-NVO was mixed with $10 \mathrm{wt} \%$ carbon nanotubes and $10 \mathrm{wt} \%$ poly(vinylidenefluoride) (PVDF) in the solvent of $N$-methylpyrrolidone (NMP). The as-formed slurry was then pasted onto the titanium foils (diameter: $1 \mu \mathrm{m}$ ) to achieve the cathode part, which was later coupled with zinc foils anode and $1 \mathrm{M} \mathrm{Zn}\left(\mathrm{ClO}_{4}\right)_{2}$ in propylene carbonate (PC) as the electrolyte, for complete coin-cell configuration. In addition, quasi-solid-state 
ZIBs were assembled using the as-prepared 3D-NVO cathode, zinc foil anode, and the electrolyte of solid polymer membranes. The solid membranes were prepared as follows: (1) $0.264 \mathrm{~g} \mathrm{Zn}\left(\mathrm{ClO}_{4}\right)_{2}$ and $0.75 \mathrm{~g}$ PVDF were initially dissolved in $10 \mathrm{~mL} \mathrm{~N}, \mathrm{~N}$-dimethylformamide (DMF) under magnetic stirring, (2) adding $1 \mathrm{~mL}$ of zinc bis(trifluoromethanesulfonyl)imide (Zn(TFSI) $)_{2}, 1 \mathrm{M}$ ) in 1-ethyl-3-methylimidazolium bis(trifluoromethylsulfonyl) imide (EMIMTFSI), and (3) the mixed solution was poured into the mold and dried at vacuum oven for $8 \mathrm{~h}$ under $80{ }^{\circ} \mathrm{C}$. The tests were carried out on a Neware battery system, and the discharging/charging profiles were performed within $0.3-1.5 \mathrm{~V}$ (vs. $\mathrm{Zn}^{2+} / \mathrm{Zn}$ ). Cyclic voltammetry was performed with a IVIUM electrochemical workstation.

\section{Results and Discussion}

In this paper, 3D-NVO cathode materials were successfully synthesized by reacting ammonium metavanadate $\left(\mathrm{NH}_{4} \mathrm{VO}_{3}\right)$ with oxalic acid $\left(\mathrm{H}_{2} \mathrm{C}_{2} \mathrm{O}_{4}\right)$ in aqueous solution through a one-pot microwave-assisted hydrothermal method. Figure $2 b$ shows the XRD pattern of 3D-NVO sample. All the diffraction peaks are readily assigned to a pure monoclinic structure of $\mathrm{NH}_{4} \mathrm{~V}_{4} \mathrm{O}_{10}$ (JCPDS Card No. 31-0075), agreeing well with the literature $[49,57]$. The intensity of $(001)$ peak is extremely high, which illustrates the preferential exposure of (001) surface facets. Its elemental composition and chemical states were further identified by X-ray photoelectron spectroscopy (XPS). V, N, and $\mathrm{O}$ elements are presented, and two peaks at approximately 401.2 and $530.2 \mathrm{eV}$ are the characteristic binding energies of $\mathrm{N}$ and $\mathrm{O}$, respectively (Fig. S2). Meanwhile, high-resolution XPS spectrum of V 2p in Fig. 2c is split into the overlapped $\mathrm{V}^{5+}\left(2 \mathrm{p}_{3 / 2}: 517.4 \mathrm{eV}\right)$ and $\mathrm{V}^{4+}$ $\left(2 \mathrm{p}_{3 / 2}: 516.4 \mathrm{eV}\right)$ peaks, displaying the average vanadium oxidation state of +4.74 , proving the sectional reduction of pentavalent vanadium by oxalic acid [58].

SEM and TEM were employed to examine the morphology and microstructure of the as-prepared 3D-NVO. The low-magnification SEM image in Fig. 2d reveals the uniform 3D microflower-like morphology of the 3D-NVO, and each of them shows a diameter in the range of 4-10 $\mu \mathrm{m}$. Magnified SEM image (Fig. 2e) and TEM examination (Figs. $2 \mathrm{f}$ and $\mathrm{S} 3$ ) indicate that hierarchical microflowers are constructed by numerous NVO nanobelts with a length of
2-5 $\mu \mathrm{m}$ and a width of $100-200 \mathrm{~nm}$. Moreover, a laterallying nanobelt found in Fig. $2 \mathrm{f}$ displays the side view of the nanobelt and its thickness is estimated to be around $20 \mathrm{~nm}$. The high-resolution TEM (HRTEM) observation further demonstrates that the interplanar spacing of the layered $\mathrm{NVO}$ along $c$-axis direction is as large as $0.93 \mathrm{~nm}$ (inset of Fig. 2f). The selected-area electron diffraction (SAED) pattern of an individual NVO nanobelt (Fig. $2 \mathrm{~g}$ ) unveils single-crystalline character by showing well-defined diffraction spots (zone axis: [001]). HRTEM image glimpsed from the middle of a nanobelt (Fig. 2h, upper panel) exhibits two sets of lattices with $d$-spacings of 0.184 and $0.193 \mathrm{~nm}$, matching well with the (020) and (-205) planes of monoclinic NVO, respectively. In addition, from the HRTEM observation on the edge of a nanobelt (Fig. 2h, bottom panel), we can see the lattice fringes ( $d$-spacing of $0.184 \mathrm{~nm}$ for (020) planes) perpendicular to the length of the nanobelt, illustrating the preferential orientation growth along the [010] direction. Furthermore, Fig. 2i depicts the scanning TEM (STEM) and the corresponding elemental mapping of a NVO nanobelt, indicating uniform distribution of $\mathrm{V}, \mathrm{N}$, and $\mathrm{O}$ elements.

The in situ self-assembly of NVO nanobelts into 3D microflowers is driven by microwave irradiation heating $(\mathrm{MIH})$, which is a very fast $(30 \mathrm{~min})$. To announce the importance of MIH, conventional autoclave hydrothermal reactions (C-HT) at different times were carried out, while other experimental parameters are kept the same as those of MIH. It was found that, as shown in Fig. S4, only NVO nanobelts without 3D assemblies could be produced in C-HT even after prolonged reaction time of 2,6 , and $12 \mathrm{~h}$ (almost no sample was presented after $30 \mathrm{~min}$ of reaction). Furthermore, under the method of C-HT, NVO nanobelt morphology was also widely observed in the literature using similar reactants, reaction temperatures, and time $[41,42,46,49$, 50]. Hence, the role of MIH appears to be critical for a successful growth of the 3D-NVO, which can directly interact with reactants by producing more homogeneous heat distribution at molecular level throughout the entire solution as compared to C-HT (Fig. S5), hence reducing reaction time and enhancing reaction kinetics [59].

Electrochemical performance of the 3D-NVO cathode was evaluated in coin-type cells. Figure 3 a shows its voltage-capacity profiles at a low rate of $100 \mathrm{~mA} \mathrm{~g}^{-1}$ for the first three cycles. $\mathrm{Zn}^{2+}$ intercalation (discharge) and deintercalation (charge) are represented by the S-shaped sloping curves, which correspond to solid solution processes. After 

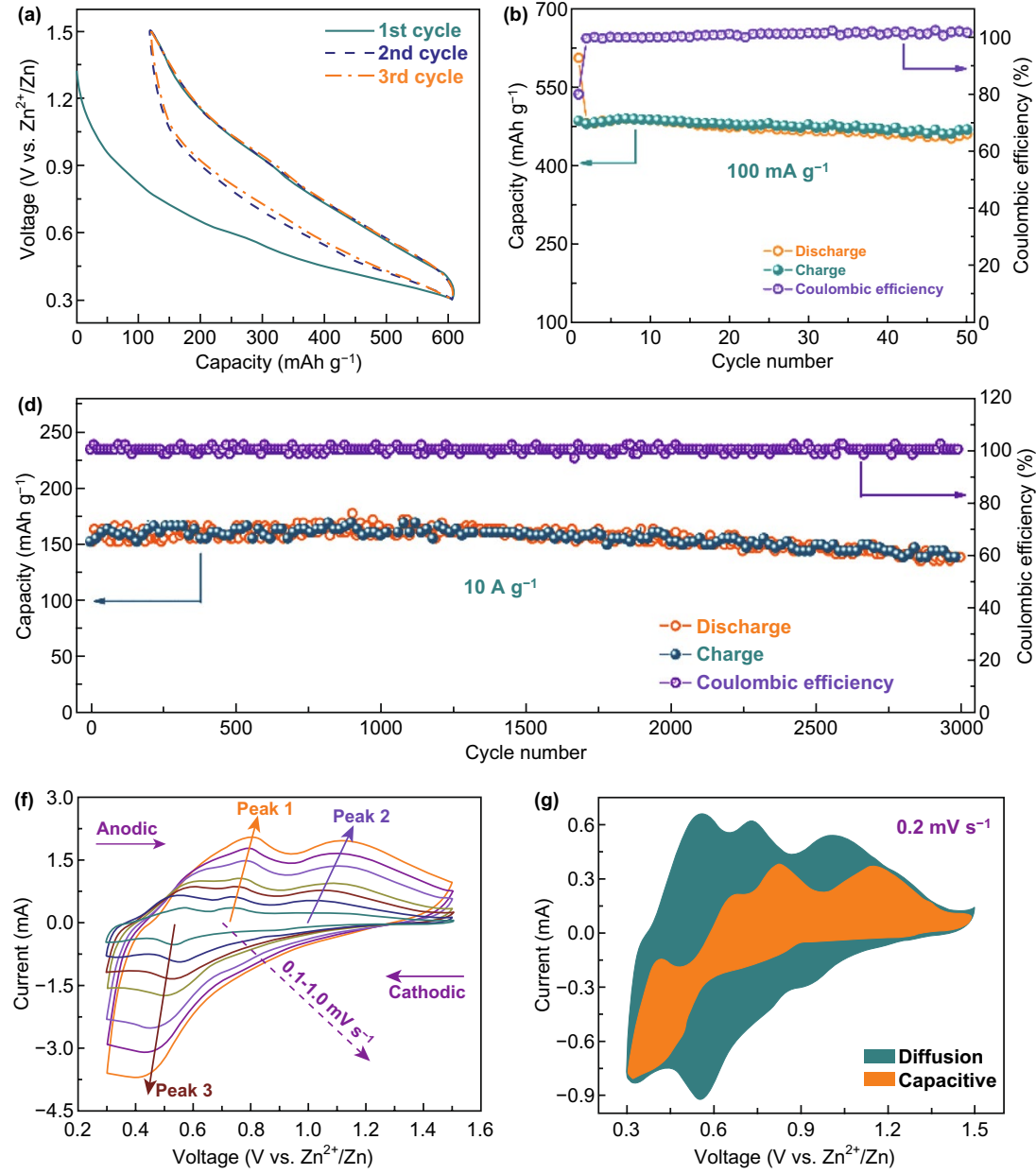
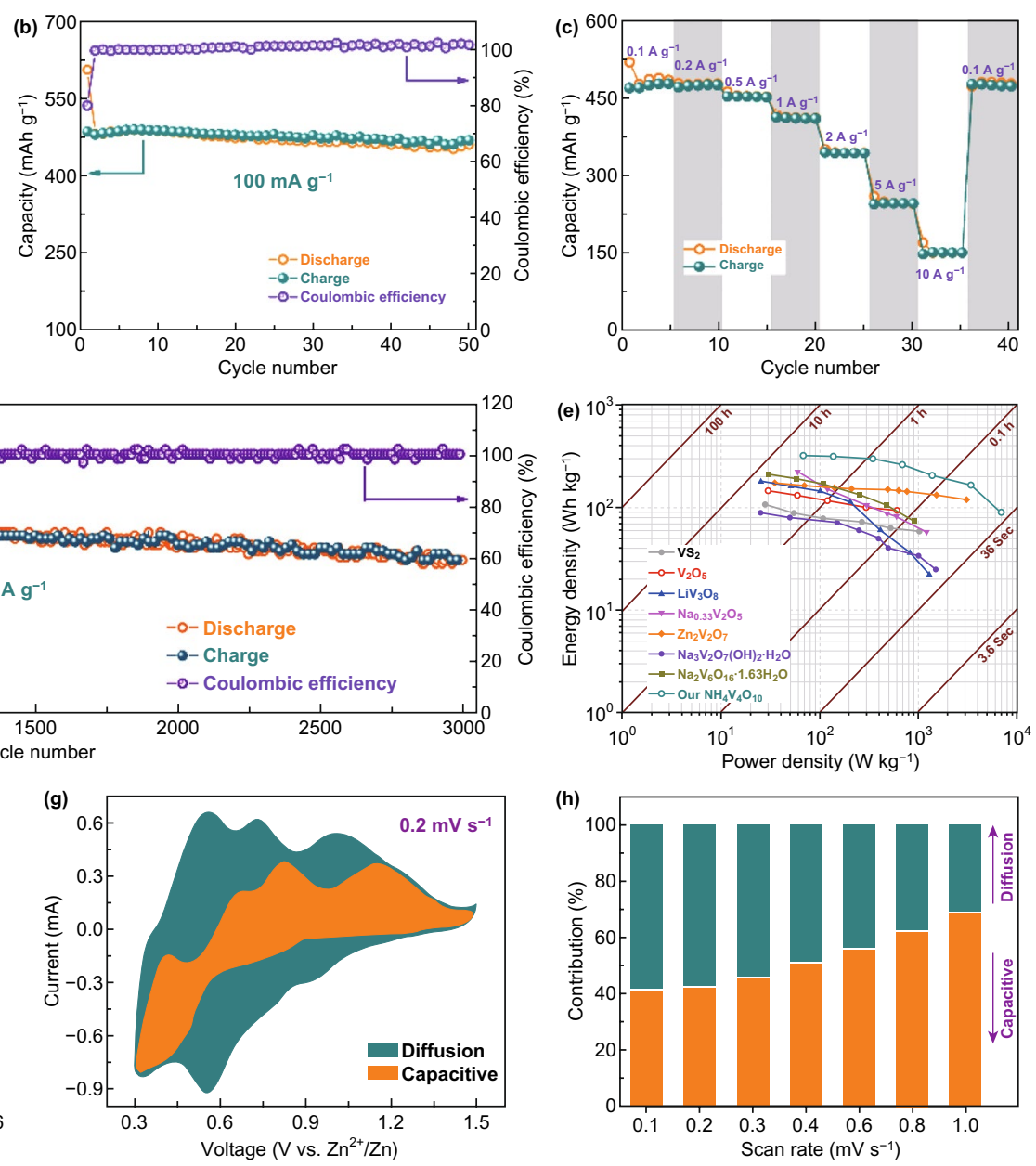

Fig. 3 Electrochemical characterization of the 3D-NVO cathode. a Galvanostatic discharge and charge profiles for the first three cycles at $100 \mathrm{~mA} \mathrm{~g}^{-1}$. b Cycling performance at $100 \mathrm{~mA} \mathrm{~g}^{-1}$. c Rate capability. d Long-term cycling performance at a high rate of $10 \mathrm{~A} \mathrm{~g}$. Ragone plots of our 3D-NVO cathode, compared with some advanced vanadium-based cathodes for ZIBs. f CV curves at scan rates from 0.1 to $1.0 \mathrm{mV} \mathrm{s}^{-1}$. $\mathbf{g}$ Evaluation of capacitive contribution to the total charge storage (e.g., $0.2 \mathrm{mV} \mathrm{s}^{-1}$ ). $\mathbf{h}$ Contribution ratio of the capacitive-controlled and diffusion-controlled capacities at various scan rates

the first discharge, a capacity of $607 \mathrm{mAh} \mathrm{g}^{-1}$ is achieved, and followed by a charge capacity of $487 \mathrm{mAh} \mathrm{g}^{-1}$, denoting a Coulombic efficiency (CE) of $80 \%$. As shown in Fig. 3b, the capacity illustrates an outstanding cycling performance with almost no capacity fading during the subsequent cycles, and the CE is close to $100 \%$ from the 2 nd cycle onward. Remarkably, the sustained reversible capacity ( $485 \mathrm{mAh} \mathrm{g}^{-1}$, i.e., uptake/release of $3.5 \mathrm{Zn}$ per unit formula of NVO) is extraordinarily high, which has not yet been achieved for the reported ZIB cathodes (Table S1). Good highrate performance is essential to build fast-charging ZIBs. As demonstrated in Fig. 3c, the cell was run between 0.1 and $10 \mathrm{~A} \mathrm{~g}^{-1}$. Capacities of 486, 475, 453, 411, 343, and
$246 \mathrm{mAh} \mathrm{g}^{-1}$ are displayed at current densities of $0.1,0.2$, $0.5,1.0,2.0$, and $5.0 \mathrm{~A} \mathrm{~g}^{-1}$, respectively, and the sloping discharge/charge profiles are also well retained at various rates (Fig. S6). Moreover, a capacity of $142 \mathrm{mAh} \mathrm{g}^{-1}$ is still delivered even at $10 \mathrm{~A} \mathrm{~g}^{-1}$ (approximately $50 \mathrm{~s}$ to full discharge/charge). Particularly, even after rapid charging/ discharging, the 3D-NVO can still recover to high capacity of $478 \mathrm{mAh} \mathrm{g}^{-1}$ when the rate is returned to $0.1 \mathrm{~A} \mathrm{~g}^{-1}$. Furthermore, the stability of this cathode at $10 \mathrm{~A} \mathrm{~g}^{-1}$ is superior, showing almost no capacity loss after 3000 cycles (Fig. 3d) and unchanged discharge/charge profiles (Fig. S7). In contrast, the cathode of NVO nanobelts obtained from the traditional hydrothermal method (Fig. S4c, d) demonstrates 
a fast capacity decaying (only $58 \%$ capacity retention after 300 cycles) at $10 \mathrm{~A} \mathrm{~g}^{-1}$ (Fig. S8), confirming the superiority of the 3D-NVO cathode.

The 3D-NVO is placed in a Ragone plot (energy density vs. power density) based on working potential, specific capacity, and current density for performance evaluation. Encouragingly, as displayed in Fig. 3e, our 3D-NVO exhibits a very high energy density of $321 \mathrm{Wh} \mathrm{kg}^{-1}$ at a specific power of $69 \mathrm{~W} \mathrm{~kg}^{-1}$. Furthermore, an outstanding power density of $6.9 \mathrm{~kW} \mathrm{~kg}^{-1}$ (corresponding energy density: $90 \mathrm{Wh} \mathrm{kg}^{-1}$ ) can also be obtained. These results pass significantly beyond most advanced ZIB cathodes such as $\mathrm{VS}_{2}$ [37], $\mathrm{V}_{2} \mathrm{O}_{5}$ [25], $\mathrm{LiV}_{3} \mathrm{O}_{8}$ [32], $\mathrm{Na}_{0.33} \mathrm{~V}_{2} \mathrm{O}_{5}$ [60], $\mathrm{Zn}_{2} \mathrm{~V}_{2} \mathrm{O}_{7}$ [61], $\mathrm{Na}_{3} \mathrm{~V}_{2} \mathrm{O}_{7}(\mathrm{OH})_{2} \cdot 2 \mathrm{H}_{2} \mathrm{O}$ [62], and $\mathrm{Na}_{2} \mathrm{~V}_{6} \mathrm{O}_{16} \cdot 1.63 \mathrm{H}_{2} \mathrm{O}$ [63], evidencing the superior ZIBs performance of our 3D-NVO materials.

To understand the electrochemical $\mathrm{Zn}^{2+}$ ion storage kinetics of 3D-NVO cathode, cyclic voltammetry (CV) was performed under scan rates of $0.1-1.0 \mathrm{mV} \mathrm{s}^{-1}$ (Fig. 3f). The redox peaks are gradually broadened and slightly shifted with increasing scan rate, but the $\mathrm{CV}$ contour is maintained. Their current $(i)$, in principle, is obedient to a power-law relationship with the scan rate $(\nu)$ via the equation: $i=\mathrm{a} \nu^{b}$. When the $b$ value is 0.5 , it represents a diffusion-controlled process, whereas $b=1.0$ stands for a capacitive process. Accordingly, the data in Fig. S9 reveal a combination of $\mathrm{Zn}^{2+}$ ion intercalation and capacitive reactions in the 3D-NVO cathode. ( $b$ values range from 0.78 to 0.86 for the marked cathodic and anodic peaks in Fig. 3f.) Again, based on the equation of $i(\mathrm{~V})=k_{1} \nu$ (capacitive effect) $+k_{2} \nu^{1 / 2}$ (diffusion effect), their proportion in the total stored charge can be quantified (e.g., the orange area in Fig. $3 \mathrm{~g}$ corresponds to the capacitive contribution). Figure $3 \mathrm{~h}$ illustrates the contributions from the two different charge storage mechanisms, and we find that the capacitive contribution increases from 40.8 to $68.4 \%$ with an increasing scan rate $\left(0.1-1.0 \mathrm{mV} \mathrm{s}^{-1}\right)$, which is primary factor that enables fast reaction kinetics and superior high-rate performance.

To investigate the storage mechanism of $\mathrm{Zn}^{2+}$ ion in the 3D-NVO cathode, ex situ XRD experiments at different charge-discharge states were performed to examine its structural evolution (Fig. 4a). Clearly, there is no significant change in the XRD patterns under various states of discharge/charge and the characteristic peaks of $\mathrm{NH}_{4} \mathrm{~V}_{4} \mathrm{O}_{10}$ located at around $9.0^{\circ}(001), 25.5^{\circ}(110), 27.7^{\circ}(111), 34.0^{\circ}$ $(-311)$, and $44.6^{\circ}(-205)$ are retained without detecting any new diffraction peaks, which is indicative of the well-preserved lamellar structure. In addition, with a careful observation, it is found that the (001) peak is slightly shift toward lower angles during the discharge process, confirming the $\mathrm{Zn}^{2+}$ ion intercalation reaction mechanism with an expansion of the $\mathrm{NH}_{4} \mathrm{~V}_{4} \mathrm{O}_{10}$ interlayer spacing. When $\mathrm{Zn}^{2+}$ ions are completely released, this peak can be recovered, demonstrating the reversible behavior of the $\mathrm{NH}_{4} \mathrm{~V}_{4} \mathrm{O}_{10}$ lattice layer. The varying of vanadium chemical states upon $\mathrm{Zn}^{2+}$ ion (de) intercalation was further evaluated by ex situ XPS analysis (Fig. 4b). At the end of the $1^{\text {st }}$ discharge state, the $\mathrm{V} 2 \mathrm{p}$ peaks can be fitted to $\mathrm{V}^{3+}\left(2 \mathrm{p}_{3 / 2}: 515.5 \mathrm{eV}\right)$ specie, which is consistent with the fully discharged product $\left(\mathrm{Zn}_{3.5} \mathrm{NH}_{4} \mathrm{~V}_{4} \mathrm{O}_{10}\right)$ derived from the galvanic curve. $\left(485 \mathrm{mAh} \mathrm{g}^{-1}\right.$ corresponds to an uptake of $3.5 \mathrm{Zn}^{2+}$ ion per formula unit.) Upon subsequent charging process, the $\mathrm{V} 2 \mathrm{p}$ spectrum almost fully recovers to its pristine state $\left(\mathrm{V}^{4.74+}\right)$ in Fig. 2c. The XPS V $2 p$ spectra under the $2^{\text {nd }}$ cycle further evidence the reversible transition between $\mathrm{V}^{4.74+}$ and $\mathrm{V}^{3+}$ via the reaction of $\mathrm{NH}_{4} \mathrm{~V}_{4} \mathrm{O}_{10}+3.5 \mathrm{Zn}^{2+}+7.0 \mathrm{e}^{-} \leftrightarrow \mathrm{Zn}_{3.5} \mathrm{NH}_{4} \mathrm{~V}_{4} \mathrm{O}_{10}$. Furthermore, SEM images of the cycled 3D-NVO cathode reveal that the pristine 3D microflower-like structure is well maintained (Fig. 4c), and the surface of NVO nanobelt is very smooth without experiencing severe pulverization (Fig. 4d). The HRTEM image with clear lattice fringes and the spotted SAED pattern suggests its highly crystalline nature is preserved (Fig. 4e). The scanning TEM (STEM) image and the corresponding elemental mapping illustrate a homogeneous distribution of $\mathrm{V}, \mathrm{O}, \mathrm{N}$, and $\mathrm{Zn}$ in the full discharged $\mathrm{NVO}$ nanobelt (Fig. 4f). Additionally, the crystal structure of $\mathrm{NH}_{4} \mathrm{~V}_{4} \mathrm{O}_{10}$ is still retained after 100 cycles at $10 \mathrm{~A} \mathrm{~g}^{-1}$ (Fig. S10). On the basis of these ex situ XRD, XPS, SEM, and TEM results, we believe that the crystal structure and microstructure of our 3D-NVO cathode are highly stable and reversible upon $\mathrm{Zn}^{2+}$ ion intercalation/deintercalation, confirming superior electrochemical performance.

Solid-state (quasi-solid-state) batteries with high safety are appealing great attention for energy storage applications [64-67]. Hence, we assembled a quasi-solid-state ZIB based on 3D-NVO cathode, zinc anode, and the electrolyte and separator of poly(vinylidenefluoride)- $\mathrm{Zn}\left(\mathrm{ClO}_{4}\right)_{2}$-based polymer membrane (Fig. 5a). Figure 5b shows the charge-discharge curves at $100 \mathrm{~mA} \mathrm{~g}^{-1}$. Obviously, the profiles are the same as those of liquid ZIB in Fig. 3a, sharing the above-mentioned $\mathrm{Zn}^{2+}$ (de) intercalation mechanism. During the first cycle, specific capacities of 320 (discharge) and $315 \mathrm{mAh} \mathrm{g}^{-1}$ (charge) are achieved 

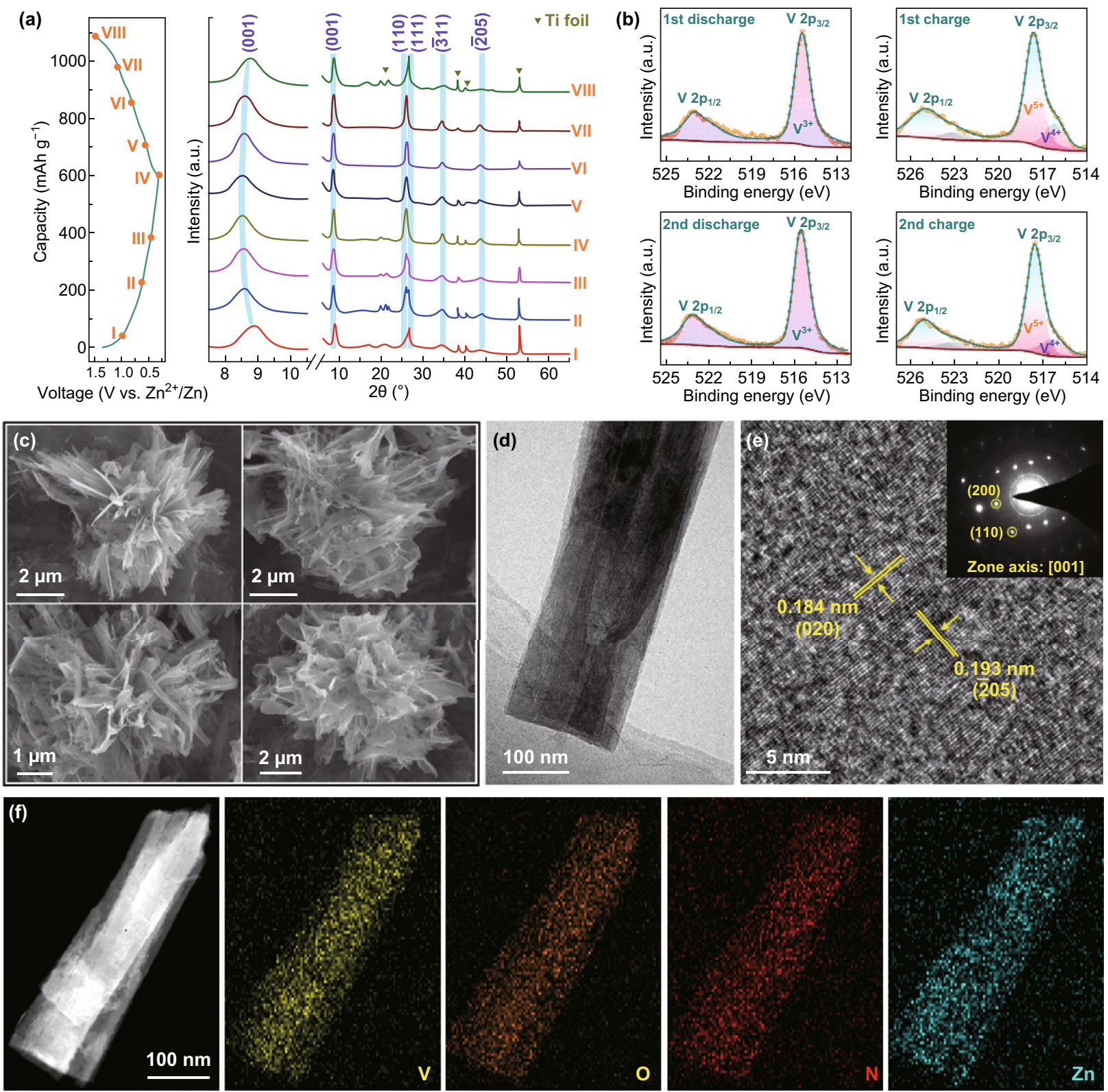

Fig. 4 Postmortem analysis of the 3D-NVO cathode. a Ex situ XRD patterns during the first cycle. b High-resolution XPS spectra of the V 2p region at fully discharged and charged states during the first two cycles. $\mathbf{c}$ SEM, $\mathbf{d}$ TEM, e HRTEM (inset: SAED pattern), and $\mathbf{f}$ STEM and the corresponding elemental mapping images of the cathode after 50 cycles at $100 \mathrm{~mA} \mathrm{~g}^{-1}$

with a CE of $98 \%$. Remarkably, in the following cycles, the specific capacity is slightly increased (corresponding to the activation process) and stabilized at $378 \mathrm{mAh} \mathrm{g}^{-1}$ with $\mathrm{CE}$ of about $100 \%$ after 50 cycles (Fig. 5c), which is much higher than state-of-the-art quasi-solid-state ZIBs (e.g., $200 \mathrm{mAh} \mathrm{g}^{-1}$ for zinc orthovanadate array//Zn array [68], and $300 \mathrm{mAh} \mathrm{g}^{-1}$ for $\mathrm{V}_{5} \mathrm{O}_{12} \cdot 6 \mathrm{H}_{2} \mathrm{O}$ nanobelts//Zn foil [69], etc.), making it promising for solid-state energy storage systems. 

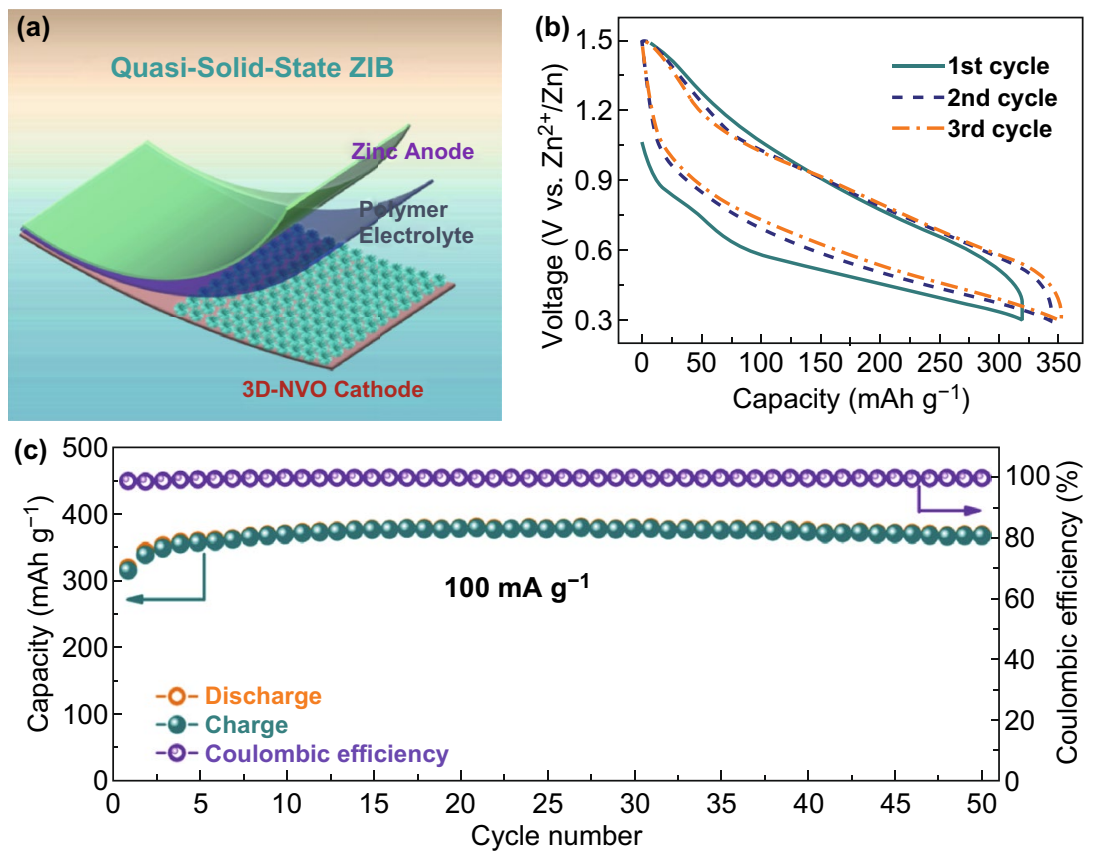

Fig. 5 a Schematic illustration of the configuration of the quasi-solid-state ZIB composed of the 3D-NVO cathode. b The charge/discharge profiles for initial three cycles and cycling performance at $100 \mathrm{~mA} \mathrm{~g}^{-1}$

\section{Conclusions}

In summary, 3D-NVO cathode was created with high capacity for ZIBs. Firstly, the first-principles calculations were carried out to confirm feasibility of $\mathrm{Zn}^{2+}$ intercalation into monoclinic NVO, in which the intercalates tend to accommodate in the interlayer region of NVO along the [010] direction. Subsequently, to enhance the $\mathrm{Zn}^{2+}$ ion diffusion kinetics and maintain the structural integrity of the electrode during long-term cycling process, a 3D flower-like architecture assembled by NVO nanobelts was designed and fabricated using a microwave-assisted hydrothermal method. In ZIB application, this 3D-NVO cathode can bring a large reversible capacity of $485 \mathrm{mAh} \mathrm{g}^{-1}$ (corresponds to energy density of $321 \mathrm{Wh} \mathrm{kg}^{-1}$ ) under current density of $0.1 \mathrm{~A} \mathrm{~g}^{-1}$. Additionally, superior long-term (3000 times) high-rate cycling performance is demonstrated (i.e., power density: $6.9 \mathrm{~kW} \mathrm{~kg}^{-1}$ ). Postmortem investigation of cycled 3D-NVO further identifies that $3.5 \mathrm{Zn}^{2+}$ ion is taken up upon intercalation through the following reaction: $\mathrm{NH}_{4} \mathrm{~V}_{4} \mathrm{O}_{10} \leftrightarrow \mathrm{Zn}_{3.5} \mathrm{NH}_{4} \mathrm{~V}_{4} \mathrm{O}_{10}$ without affecting the crystallinity and microstructure of the pristine 3D-NVO. Finally, a high-capacity $\left(378 \mathrm{mAh} \mathrm{g}^{-1}\right)$ quasi-solid-state ZIB composed of the 3D-NVO cathode is developed.
Acknowledgements The authors gratefully acknowledge the National Key R\&D Research Program of China (Grant No. 2018YFB0905400), National Natural Science Foundation of China (Grant Nos. 51622210, 51872277, 51802007, 21606003, 51972067, 51802044, 51672193, 51420105002, 51920105004, and U1910210), the Fundamental Research Funds for the Central Universities (WK2060140026), Guangdong Natural Science Funds for Distinguished Young Scholar (Grant No. 2019B151502039), the DNL Cooperation Fund, CAS (DNL180310), and Opening Project of CAS Key Laboratory of Materials for Energy Conversion.

Open Access This article is licensed under a Creative Commons Attribution 4.0 International License, which permits use, sharing, adaptation, distribution and reproduction in any medium or format, as long as you give appropriate credit to the original author(s) and the source, provide a link to the Creative Commons licence, and indicate if changes were made. The images or other third party material in this article are included in the article's Creative Commons licence, unless indicated otherwise in a credit line to the material. If material is not included in the article's Creative Commons licence and your intended use is not permitted by statutory regulation or exceeds the permitted use, you will need to obtain permission directly from the copyright holder. To view a copy of this licence, visit http://creativecommons.org/licenses/by/4.0/.

Electronic supplementary material The online version of this article (https://doi.org/10.1007/s40820-020-0401-y) contains supplementary material, which is available to authorized users. 


\section{References}

1. M. Li, J. Lu, Z. Chen, K. Amine, 30 years of lithium-ion batteries. Adv. Mater. 30, 1800561 (2018). https://doi. org/10.1002/adma.201800561

2. H. Tan, L. Xu, H. Geng, X. Rui, C. Li, S. Huang, Nanostructured $\mathrm{Li}_{3} \mathrm{~V}_{2}\left(\mathrm{PO}_{4}\right)_{3}$ cathodes. Small 14, 1800567 (2018). https ://doi.org/10.1002/smll.201800567

3. L. Wang, J.-L. Shi, H. Su, G. Li, M. Zubair, Y.-G. Guo, H. Yu, Composite-structure material design for high-energy lithium storage. Small 14, 1800887 (2018). https://doi.org/10.1002/ smll.201800887

4. Y. Tang, Y. Zhang, W. Li, B. Ma, X. Chen, Rational material design for ultrafast rechargeable lithium-ion batteries. Chem. Soc. Rev. 44, 5926-5940 (2015). https://doi.org/10.1039/ C4CS00442F

5. X. Xie, S. Liang, J. Gao, S. Guo, J. Guo et al., Manipulating the ion-transference kinetics and interface stability for highperformance zinc metal anode. Energy Environ. Sci. (2019). https://doi.org/10.1039/C9EE03545A

6. C. Xu, B. Li, H. Du, F. Kang, Energetic zinc ion chemistry: the rechargeable zinc ion battery. Angew. Chem. Int. Ed. 124, 957-959 (2012). https://doi.org/10.1002/ange.201106307

7. L. Zhang, L. Chen, X. Zhou, Z. Liu, Towards high-voltage aqueous metal-ion batteries beyond $1.5 \mathrm{~V}$ : The zinc/zinc hexacyanoferrate system. Adv. Energy Mater. 5, 1400930 (2015). https://doi.org/10.1002/aenm.201400930

8. H. Pan, Y. Shao, P. Yan, Y. Cheng, K.S. Han et al., Reversible aqueous zinc/manganese oxide energy storage from conversion reactions. Nat. Energy 1, 16039 (2016). https://doi. org/10.1038/nenergy.2016.39

9. B. Tang, L. Shan, S. Liang, J. Zhou, Issues and opportunities facing aqueous zinc-ion batteries. Energy Environ. Sci. 12, 3288-3304 (2019). https://doi.org/10.1039/C9EE02526J

10. B. Lee, H.R. Lee, H. Kim, K.Y. Chung, B.W. Cho, S.H. Oh, Elucidating the intercalation mechanism of zinc ions into $\alpha-\mathrm{MnO}_{2}$ for rechargeable zinc batteries. Chem. Commun. 51, 9265-9268 (2015). https://doi.org/10.1039/C5CC02585K

11. R. Trocoli, F. La Mantia, An aqueous zinc-ion battery based on copper hexacyanoferrate. Chemsuschem 8, 481-485 (2015). https://doi.org/10.1002/cssc.201403143

12. G. Li, Z. Yang, Y. Jiang, C. Jin, W. Huang, X. Ding, Y. Huang, Towards polyvalent ion batteries: a zinc-ion battery based on NASICON Structured $\mathrm{Na}_{3} \mathrm{~V}_{2}\left(\mathrm{PO}_{4}\right)_{3}$. Nano Energy 25, 211217 (2016). https://doi.org/10.1016/j.nanoen.2016.04.051

13. S. Guo, S. Liang, B. Zhang, G. Fang, D. Ma, J. Zhou, Cathode interfacial layer formation via in situ electrochemically charging in aqueous zinc-ion battery. ACS Nano 13, 13456-13464 (2019). https://doi.org/10.1021/acsnano.9b07042

14. B. Wu, G. Zhang, M. Yan, T. Xiong, P. He, L. He, X. Xu, L. Mai, Graphene scroll-coated alpha- $\mathrm{MnO}_{2}$ nanowires as highperformance cathode materials for aqueous $\mathrm{Zn}$-ion battery. Small 14, 1703850 (2018). https://doi.org/10.1002/smll.20170 3850
15. M.H. Alfaruqi, J. Gim, S. Kim, J. Song, J. Jo, S. Kim, V. Mathew, J. Kim, Enhanced reversible divalent zinc storage in a structurally stable alpha- $\mathrm{MnO}_{2}$ nanorod electrode. J. Power Sources 288, 320-327 (2015). https://doi.org/10.1016/j.jpows our.2015.04.140

16. C. Li, X. Shi, S. Liang, X. Ma, M. Han, X. Wu, J. Zhou, Spatially homogeneous copper foam as surface dendrite-free host for zinc metal anode. Chem. Eng. J. 379, 122248 (2020). https ://doi.org/10.1016/j.cej.2019.122248

17. M.H. Alfaruqi, V. Mathew, J. Gim, S. Kim, J. Song, J.P. Baboo, S.H. Choi, J. Kim, Electrochemically induced structural transformation in a gamma- $\mathrm{MnO}_{2}$ cathode of a high capacity zinc-ion battery system. Chem. Mater. 27, 3609-3620 (2015). https://doi.org/10.1021/cm504717p

18. B. Jiang, C. Xu, C. Wu, L. Dong, J. Li, F. Kang, Manganese sesquioxide as cathode material for multivalent zinc ion battery with high capacity and long cycle life. Electrochim. Acta 229, 422-428 (2017). https://doi.org/10.1016/j.elect acta.2017.01.163

19. J. Hao, J. Mou, J. Zhang, L. Dong, W. Liu, C. Xu, F. Kang, Electrochemically induced spinel-layered phase transition of $\mathrm{Mn}_{3} \mathrm{O}_{4}$ in high performance neutral aqueous rechargeable zinc battery. Electrochim. Acta 259, 170-178 (2018). https://doi. org/10.1016/j.electacta.2017.10.166

20. X. Wu, Y. Xiang, Q. Peng, X. Wu, Y. Li et al., Green-low-cost rechargeable aqueous zinc-ion batteries using hollow porous spinel $\mathrm{ZnMn}_{2} \mathrm{O}_{4}$ as the cathode material. J. Mater. Chem. A 5, 17990-17997 (2017). https://doi.org/10.1039/C7TA00100B

21. N. Zhang, F. Cheng, Y. Liu, Q. Zhao, K. Lei, C. Chen, X. $\mathrm{Liu}$, J. Chen, Cation-deficient spinel $\mathrm{ZnMn}_{2} \mathrm{O}_{4}$ cathode in $\mathrm{Zn}\left(\mathrm{CF}_{3} \mathrm{SO}_{3}\right)_{2}$ electrolyte for rechargeable aqueous $\mathrm{Zn}$-ion battery. J. Am. Chem. Soc. 138, 12894-12901 (2016). https://doi. org/10.1021/jacs.6b05958

22. J. Ding, Z. Du, L. Gu, B. Li, L. Wang, S. Wang, Y. Gong, S. Yang, Ultrafast $\mathrm{Zn}^{2+}$ intercalation and deintercalation in vanadium dioxide. Adv. Mater. 30, 1800762 (2018). https:// doi.org/10.1002/adma.201800762

23. T. Wei, Q. Li, G. Yang, C. Wang, An electrochemically induced bilayered structure facilitates long-life zinc storage of vanadium dioxide. J. Mater. Chem. A 6, 8006-8012 (2018). https://doi.org/10.1039/C8TA02090F

24. P. Senguttuvan, S.-D. Han, S. Kim, A.L. Lipson, S. Tepavcevic et al., A high power rechargeable nonaqueous multivalent $\mathrm{Zn} /$ $\mathrm{V}_{2} \mathrm{O}_{5}$ battery. Adv. Energy Mater. 6, 1600826 (2016). https:// doi.org/10.1002/aenm.201600826

25. P. Hu, M. Yan, T. Zhu, X. Wang, X. Wei et al., $\mathrm{Zn} / \mathrm{V}_{2} \mathrm{O}_{5}$ aqueous hybrid-ion battery with high voltage platform and long cycle life. ACS Appl. Mater. Interfaces 9, 42717-42722 (2017). https://doi.org/10.1021/acsami.7b13110

26. F. Liu, Z. Chen, G. Fang, Z. Wang, Y. Cai, B. Tang, J. Zhou, $\mathrm{S}$. Liang, $\mathrm{V}_{2} \mathrm{O}_{5}$ nanospheres with mixed vanadium valences as high electrochemically active aqueous zinc-ion battery cathode. Nano-Micro Letters 11, 25 (2019). https://doi. org/10.1007/s40820-019-0256-2 
27. M. Yan, P. He, Y. Chen, S. Wang, Q. Wei et al., Waterlubricated intercalation in $\mathrm{V}_{2} \mathrm{O}_{5} \cdot \mathrm{nH}_{2} \mathrm{O}$ for high-capacity and high-rate aqueous rechargeable zinc batteries. Adv. Mater. 30, 1703725 (2018). https://doi.org/10.1002/adma.201703725

28. Y. Yang, Y. Tang, G. Fang, L. Shan, J. Guo et al., $\mathrm{Li}^{+}$intercalated $\mathrm{V}_{2} \mathrm{O}_{5} \cdot \mathrm{nH}_{2} \mathrm{O}$ with enlarged layer spacing and fast ion diffusion as an aqueous zinc-ion battery cathode. Energy Environ. Sci. 11, 3157-3162 (2018). https://doi.org/10.1039/ C8EE01651H

29. D. Kundu, B.D. Adams, V.D. Ort, S.H. Vajargah, L.F. Nazar, A high-capacity and long-life aqueous rechargeable zinc battery using a metal oxide intercalation cathode. Nat. Energy 1, 16119 (2016). https://doi.org/10.1038/nenergy.2016.119

30. W. Zhang, S. Liang, G. Fang, Y. Yang, J. Zhou, Ultra-high mass-loading cathode for aqueous zinc-ion battery based on graphene-wrapped aluminum vanadate nanobelts. NanoMicro Lett. 11, 69 (2019). https://doi.org/10.1007/s4082 0-019-0300-2

31. C. Xia, J. Guo, P. Li, X. Zhang, H.N. Alshareef, Highly stable aqueous zinc-ion storage using a layered calcium vanadium oxide bronze cathode. Angew. Chem. Int. Ed. 57, 3943-3948 (2018). https://doi.org/10.1002/anie.201713291

32. M.H. Alfaruqi, V. Mathew, J. Song, S. Kim, S. Islam et al., Electrochemical zinc intercalation in lithium vanadium oxide: a high-capacity zinc-ion battery cathode. Chem. Mater. 29, 1684-1694 (2017). https://doi.org/10.1021/acs.chemm ater.6b05092

33. Q. Zheng, H. Yi, X. Li, H. Zhang, Progress and prospect for NASICON-type $\mathrm{Na}_{3} \mathrm{~V}_{2}\left(\mathrm{PO}_{4}\right)_{3}$ for electrochemical energy storage. J. Energy Chem. 27, 1597-1617 (2018). https://doi. org/10.1016/j.jechem.2018.05.001

34. V. Soundharrajan, B. Sambandam, S. Kim, M.H. Alfaruqi, D.Y. Putro et al., $\mathrm{Na}_{2} \mathrm{~V}_{6} \mathrm{O}_{16} \cdot 3 \mathrm{H}_{2} \mathrm{O}$ barnesite nanorod: an open door to display a stable and high energy for aqueous rechargeable Zn-ion batteries as cathodes. Nano Lett. 18, 2402-2410 (2018). https://doi.org/10.1021/acs.nanolett.7b05403

35. H. Geng, M. Cheng, B. Wang, Y. Yang, Y. Zhang, C. Li, Electronic structure regulation of layered vanadium oxide via interlayer doping strategy toward superior high-rate and low-temperature zinc-ion batteries. Adv. Funct. Mater. (2019). https://doi.org/10.1002/adfm.201907684

36. B. Tang, G. Fang, J. Zhou, L. Wang, Y. Lei et al., Potassium vanadates with stable structure and fast ion diffusion channel as cathode for rechargeable aqueous zinc-ion batteries. Nano Energy 51, 579-587 (2018). https://doi.org/10.1016/j.nanoe n.2018.07.014

37. P. He, M. Yan, G. Zhang, R. Sun, L. Chen, Q. An, L. Mai, Layered $\mathrm{VS}_{2}$ nanosheet-based aqueous $\mathrm{Zn}$ ion battery cathode. Adv. Energy Mater. 7, 1601920 (2017). https://doi. org/10.1002/aenm.201601920

38. N.A. Chernova, M. Roppolo, A.C. Dillon, M.S. Whittingham, Layered vanadium and molybdenum oxides: batteries and electrochromics. J. Mater. Chem. 19, 2526-2552 (2009). https://doi.org/10.1039/b819629j
39. S. Sarkar, P.S. Veluri, S. Mitra, Morphology controlled synthesis of layered $\mathrm{NH}_{4} \mathrm{~V}_{4} \mathrm{O}_{10}$ and the impact of binder on stable high rate electrochemical performance. Electrochim. Acta 132, 448-456 (2014). https://doi.org/10.1016/j.elect acta.2014.03.144

40. D. Fang, Y. Cao, R. Liu, W. Xu, S. Liu et al., Novel hierarchical three-dimensional ammonium vanadate nanowires electrodes for lithium ion battery. Appl. Surf. Sci. 360, 658-665 (2016). https://doi.org/10.1016/j.apsusc.2015.11.038

41. K.-F. Zhang, G.-Q. Zhang, X. Liu, Z.-X. Su, H.-L. Li, Large scale hydrothermal synthesis and electrochemistry of ammonium vanadium bronze nanobelts. J. Power Sources 157, 528532 (2006). https://doi.org/10.1016/j.jpowsour.2005.07.043

42. E.A. Esparcia Jr., M.S. Chae, J.D. Ocon, S.-T. Hong, Ammonium vanadium bronze $\left(\mathrm{NH}_{4} \mathrm{~V}_{4} \mathrm{O}_{10}\right)$ as a high-capacity cathode material for nonaqueous magnesium-ion batteries. Chem. Mater. 30, 3690-3696 (2018). https://doi.org/10.1021/acs. chemmater.8b00462

43. H. Fei, X. Liu, Y. Lin, M. Wei, Facile synthesis of ammonium vanadium oxide nanorods for $\mathrm{Na}$-ion battery cathodes. J. Colloid Interface Sci. 428, 73-77 (2014). https://doi. org/10.1016/j.jcis.2014.04.029

44. T. Sarkar, P. Kumar, M.D. Bharadwaj, U. Waghmare, Structural transformation during $\mathrm{Li} / \mathrm{Na}$ insertion and theoretical cyclic voltammetry of the delta- $\mathrm{NH}_{4} \mathrm{~V}_{4} \mathrm{O}_{10}$ electrode: a firstprinciples study. Phys. Chem. Chem. Phys. 18, 9344-9348 (2016). https://doi.org/10.1039/C5CP07782F

45. V. Thuan Ngoc, H. Kim, J. Hur, W. Choi, I.T. Kim, Surfactant-assisted ammonium vanadium oxide as a superior cathode for calcium-ion batteries. J. Mater. Chem. A 6, 22645-22654 (2018). https://doi.org/10.1039/C8TA07831A

46. A. Sarkar, S. Sarkar, T. Sarkar, P. Kumar, M.D. Bharadwaj, S. Mitra, Rechargeable sodium-ion battery: high-capacity ammonium vanadate cathode with enhanced stability at high rate. ACS Appl. Mater. Interfaces 7, 17044-17053 (2015). https://doi.org/10.1021/acsami.5b03210

47. D. Chen, Q. Zhang, X. Rui, H. Geng, L. Gan et al., Persistent zinc-ion storage in mass-produced $\mathrm{V}_{2} \mathrm{O}_{5}$ architectures. Nano Energy 60, 171-178 (2019). https://doi.org/10.1016/j.nanoe n.2019.03.034

48. X. Zhao, X. Zhang, D. Wu, H. Zhang, F. Ding, Z. Zhou, $\mathrm{Ab}$ initio investigations on bulk and monolayer $\mathrm{V}_{2} \mathrm{O}_{5}$ as cathode materials for $\mathrm{Li}-, \mathrm{Na}-, \mathrm{K}-$ and $\mathrm{Mg}$-ion batteries. J. Mater. Chem. A 4, 16606-16611 (2016). https://doi. org/10.1039/C6TA04986A

49. N. Wang, W. Chen, L. Mai, Y. Dai, Selected-control hydrothermal synthesis and formation mechanism of 1D ammonium vanadate. J. Solid State Chem. 181, 652-657 (2008). https://doi.org/10.1016/j.jssc.2007.12.036

50. G. Yang, T. Wei, C. Wang, Self-healing lamellar structure boosts highly stable zinc-storage property of bilayered vanadium oxides. ACS Appl. Mater. Interfaces 10, 35079-35089 (2018). https://doi.org/10.1021/acsami.8b10849 
51. J.P. Perdew, K. Burke, M. Ernzerhof, Generalized gradient approximation made simple. Phys. Rev. Lett. 77, 3865-3868 (1996). https://doi.org/10.1103/PhysRevLett.77.3865

52. P.E. Blöchl, Projector augmented-wave method. Phys. Rev. B 50, 17953-17979 (1994). https://doi.org/10.1103/PhysR evB.50.17953

53. G. Kresse, D. Joubert, From ultrasoft pseudopotentials to the projector augmented-wave method. Phys. Rev. B 59, 17581775 (1999). https://doi.org/10.1103/PhysRevB.59.1758

54. C. Persson, A.F. da Silva, Strong polaronic effects on rutile $\mathrm{TiO}_{2}$ electronic band edges. Appl. Phys. Lett. 86, 231912 (2005). https://doi.org/10.1063/1.1940739

55. G. Henkelman, B.P. Uberuaga, H. Jonsson, A climbing image nudged elastic band method for finding saddle points and minimum energy paths. J. Chem. Phys. 113, 9901-9904 (2000). https://doi.org/10.1063/1.1329672

56. J.S. Braithwaite, C.R.A. Catlow, J.D. Gale, J.H. Harding, Lithium intercalation into vanadium pentoxide: a theoretical study. Chem. Mater. 11, 1990-1998 (1999). https://doi. org $/ 10.1021 / \mathrm{cm} 980735 \mathrm{r}$

57. H.A. Abbood, H. Peng, X. Gao, B. Tan, K. Huang, Fabrication of cross-like $\mathrm{NH}_{4} \mathrm{~V}_{4} \mathrm{O}_{10}$ nanobelt array controlled by CMC as soft template and photocatalytic activity of its calcinated product. Chem. Eng. J. 209, 245-254 (2012). https://doi. org/10.1016/j.cej.2012.08.027

58. D. Chen, H. Tan, X. Rui, Q. Zhang, Y. Feng et al., Oxyvanite $\mathrm{V}_{3} \mathrm{O}_{5}$ : a new intercalation-type anode for lithium-ion battery. InfoMat 1, 251-259 (2019). https://doi.org/10.1002/ inf2.12011

59. M. Bhattacharya, T. Basak, A review on the susceptor assisted microwave processing of materials. Energy 97, 306-338 (2016). https://doi.org/10.1016/j.energy.2015.11.034

60. P. He, G. Zhang, X. Liao, M. Yan, X. Xu, Q. An, J. Liu, L. Mai, Sodium ion stabilized vanadium oxide nanowire cathode for high-performance zinc-ion batteries. Adv. Energy Mater. 8, 1702463 (2018). https://doi.org/10.1002/aenm.201702463

61. B. Sambandam, V. Soundharrajan, S. Kim, M.H. Alfaruqi, J. Jo et al., Aqueous rechargeable $\mathrm{Zn}$-ion batteries: an imperishable and high-energy $\mathrm{Zn}_{2} \mathrm{~V}_{2} \mathrm{O}_{7}$ nanowire cathode through intercalation regulation. J. Mater. Chem. A 6, 3850 3856 (2018). https://doi.org/10.1039/C7TA11237H

62. C. Xia, J. Guo, Y. Lei, H. Liang, C. Zhao, H.N. Alshareef, Rechargeable aqueous zinc-ion battery based on porous framework zinc pyrovanadate intercalation cathode. Adv. Mater. 30, 1705580 (2018). https://doi.org/10.1002/adma.201705580

63. P. Hu, T. Zhu, X. Wang, X. Wei, M. Yan et al., Highly durable $\mathrm{Na}_{2} \mathrm{~V}_{6} \mathrm{O}_{16} \cdot 1.63 \mathrm{H}_{2} \mathrm{O}$ nanowire cathode for aqueous zincion battery. Nano Lett. 18, 1758-1763 (2018). https://doi. org/10.1021/acs.nanolett.7b04889

64. A. Manthiram, X. Yu, S. Wang, Lithium battery chemistries enabled by solid-state electrolytes. Nat. Rev. Mater. 2, 16103 (2017). https://doi.org/10.1038/natrevmats.2016.103

65. X. Chen, W. He, L. Ding, S. Wang, H. Wang, Enhancing interfacial contact in all solid state batteries with a cathodesupported solid electrolyte membrane framework. Energy Environ. Sci. 12, 938-944 (2019). https://doi.org/10.1039/ C8EE02617C

66. Z. Jiang, H. Xie, S. Wang, X. Song, X. Yao, H.H. Wang, Perovskite membranes with vertically aligned microchannels for all-solid-state lithium batteries. Adv. Energy Mater. 8, 1801433 (2018). https://doi.org/10.1002/aenm.201801433

67. H. Xiang, J. Chen, Z. Li, H. Wang, An inorganic membrane as a separator for lithium-ion battery. J. Power Sources 196, 8651-8655 (2011). https://doi.org/10.1016/j.jpows our.2011.06.055

68. D. Chao, C. Zhu, M. Song, P. Liang, X. Zhang et al., A highrate and stable quasi-solid-state zinc-ion battery with novel 2D layered zinc orthovanadate array. Adv. Mater. 30, 1803181 (2018). https://doi.org/10.1002/adma.201803181

69. N. Zhang, M. Jia, Y. Dong, Y. Wang, J. Xu, Y. Liu, L. Jiao, F. Cheng, Hydrated layered vanadium oxide as a highly reversible cathode for rechargeable aqueous zinc batteries. Adv. Funct. Mater. 29, 1807331 (2019). https://doi.org/10.1002/ adfm.201807331 